\title{
Effect of Endocrine Therapy on Quality of Life and Cognitive Functions in Patients with Breast Cancer
}

\author{
Saadettin Kilickap ${ }^{a}$ Mutlu Hayran ${ }^{b}$ Banu Cakir $^{c}$ Nesrin Cilingiroglu ${ }^{c}$ \\ Mustafa Erman ${ }^{\mathrm{b}}$ Guldal Buyukdamgaci $^{\mathrm{d}}$ Yavuz Ozisik $^{\mathrm{e}}$ \\ aDepartment of Medical Oncology, Cumhuriyet University Faculty of Medicine, Sivas, \\ ${ }^{b}$ Department of Preventive Oncology, Hacettepe University Institute of Oncology, Ankara, \\ ${ }^{\circ}$ Department of Public Health, Hacettepe University Faculty of Medicine, Ankara, \\ ${ }^{\mathrm{d}}$ Research Project Office, Bogazici University, Istanbul, \\ eDepartment of Medical Oncology, Hacettepe University Institute of Oncology, Ankara, Turkey
}

\section{Keywords}

Aromatase inhibitors . Breast cancer - Cognitive function . Endocrine therapy - Quality of life · Tamoxifen

\section{Summary}

Background: The use of endocrine therapy (ET) in postmenopausal breast cancer patients may affect their cognitive status. This study aims to assess the effects of tamoxifen and aromatase inhibitors (Als) on quality of life ( $\mathrm{QoL}$ ) and cognitive functions in breast cancer patients. Patients and Methods: The study included 101 patients receiving tamoxifen, 97 patients receiving Als, and 95 patients without any ET. All patients completed both the European Organization for Research and Treatment of Cancer (EORTC) QLQ-C30 and the Short Form-12 (SF-12) questionnaires. Results: The patients' characteristics were similar between the groups. The mean duration of ET was 2.6 years for tamoxifen and 2.5 years for Als. EORTC QLQ-C30 global scores and cognitive functioning scores as well as SF-12 mental scorings (mcs) were found not significantly different between patients without any ET and those receiving tamoxifen or Als $(p=0.529, p=0.333$, and $p=0.452$, respectively). SF-12 mcs correlated moderately with EORTC QLQC30 global scores for the 3 treatment groups (all $p$ values $<0.001)$. Conclusion: Our study suggests that QoL and cognitive functions are similar in patients receiving Als or tamoxifen. Moreover, it appears that these parameters also do not differ in patients with respect to the use of ET.

\section{Schlüsselwörter}

Aromatasehemmer - Mammakarzinom - Kognitive Funktion . Endokrine Therapie · Lebensqualität · Tamoxifen

\section{Zusammenfassung}

Hintergrund: Es ist möglich, dass der Einsatz endokriner Therapie bei postmenopausalen Mammakarzinom-Patientinnen deren kognitiven Status beeinflusst. Ziel der vorliegenden Studie ist es, die Auswirkungen von Tamoxifen und Aromatasehemmern auf die Lebensqualität und kognitive Funktionen von Mammakarzinom-Patientinnen zu bewerten. Patientinnen und Methoden: Von der Studienpopulation erhielten 101 Patientinnen Tamoxifen, 97 Aromatasehemmer und 95 keinerlei endokrine Therapie. Alle Patientinnen füllten sowohl den EORTC (European Organization for Research and Treatment of Cancer)-OLQ-C30- als auch den SF-12 (Short Form-12)-Fragebogen aus. Ergebnisse: Die Patientenmerkmale waren in allen Gruppen vergleichbar. Die mittlere Behandlungsdauer war 2,6 Jahre im Falle von Tamoxifen und 2,5 Jahre im Falle von Aromatasehemmern. Die Auswertung sowohl des EORTC-QLO-C30-Fragebogens (global sowie kognitive Funktion) als auch des SF-12-Fragebogens (mentale Bewertung) zeigten keine signifikanten Unterschiede zwischen Patientinnen ohne endokrine Therapie und Patientinnen unter Behandlung mit Tamoxifen bzw. Aromatasehemmern ( $p=0,529, p=0,333$ bzw. $p=$ 0,452 ). In den 3 Behandlungsgruppen war die mentale Bewertung mit SF-12 mittelgradig mit der globalen EORTCQLQ-C30-Bewertung korreliert (alle p-Werte < 0,001). Schlussfolgerung: Unsere Studie deutet an, dass Patientinnen unter Behandlung mit Tamoxifen bzw. Aromatasehemmern vergleichbare Lebensqualität bzw. kognitive Funktionen aufweisen. Desweiteren erscheinen diese Parameter keine Unterschiede in Bezug auf den Einsatz endokriner Therapie zu zeigen.

\section{KARGER}

Fax +497614520714

Information@Karger.com

www.karger.com (c) 2013 S. Karger GmbH, Freiburg

$1661-3791 / 13 / 0082-0128 \$ 38.00 / 0$

Accessible online at:

www.karger.com/brc
Saadettin Kilickap, MD

Cumhuriyet University Faculty of Medicine

Department of Medical Oncology

58100 Sivas, Turkey

skilickap@yahoo.com 


\section{Introduction}

Breast cancer is the most common cancer in females and the second most common cause of death in the world. Approximately three-quarters of all invasive breast tumors are estrogen receptor (ER)- and/or progesterone receptor-positive, and these patients are classified as having hormone receptorpositive $(\mathrm{HR}+)$ disease [1]. HR+ patients benefit from endocrine therapy (ET) such as tamoxifen as well as aromatase inhibitors (AIs) including letrozole, anastrozole, and exemestane. While AIs are only used in postmenopausal breast cancer patients, tamoxifen, a selective ER-modulating agent, is an effective treatment option for pre- and postmenopausal patients. Currently, ET is recommended to be administered for 5 years as adjuvant treatment for early breast cancer. Although both tamoxifen and AIs are well tolerated and have excellent outcomes, their side effects differ considerably. Hot flushes, vaginal discharge and bleeding, fatigue, and an increased risk of endometrial cancer and thromboembolic events are common side effects reported in patients treated with tamoxifen. AI-related toxicities mainly include musculoskeletal side effects such as arthralgia, arthritis, osteopenia, osteoporosis and osteoporosis-related fractures, hyperlipidemia, as well as coronary heart disease [2-5]. The state of cognitive functions after AI use has not yet been fully established. The BIG-1-98 study demonstrated that the use of letrozole improved cognitive functions in comparison to tamoxifen [6]. However, other studies revealed that ET with tamoxifen and AIs had no detectable effects on cognitive functions in patients with breast cancer [7]. This study aimed to assess the effects of ET with tamoxifen or AIs on quality of life (QoL) and cognitive functions in patients with breast cancer.

\section{Patients and Methods}

This cross-sectional study included breast cancer patients who were treated in the Department of Medical Oncology at the Hacettepe University Institute of Oncology between June 2007 and March 2009. The demographic, clinical, and pathologic features of all patients were recorded in a Microsoft Excel 2007-based database. Educational level, income, comorbidities, and marital status of each patient were recorded in the database at the time of questionnaire completion. To evaluate the effects of ET on cognitive functions, patients enrolled in the study were categorized into 3 different groups: patients receiving tamoxifen or patients receiving AIs or patients not receiving any hormonal agents. Patients who were treated for less than 6 months with ET agents, who discontinued ET for more than 3 months, and who were older than 70 years of age were excluded. The QoL of the patients was assessed with Turkish versions of the European Organization for Research and Treatment of Cancer (EORTC) QLQ-C30 and Short Form-12 (SF-12) questionnaires. The breast cancer follow-up form and the QoL survey forms were filled in under the supervision of 2 trained interviewers using a face-to-face interview method during routine periodic follow-up sessions for each patient. The study protocol was approved by the Ethical Committee of the Hacettepe University Faculty of Medicine before the initiation of the survey, and a written informed consent was obtained from each patient (approval no.: TBK07/4-5; approval date: 01.03.2007).

\section{Quality of Life Scales and Their Evaluation}

A different database was established to assess the QoL scale forms using the Statistical Package for Social Sciences (SPSS) version 15.0 (IBM Corporation, Armonk, NY, USA). The information in the questionnaires was transferred to the database. QoL scores were calculated using the formulas below.

\begin{tabular}{|c|c|c|c|c|}
\hline & $\begin{array}{l}\text { No ET } \\
(\mathrm{n}=95)\end{array}$ & $\begin{array}{l}\text { TMX } \\
(\mathrm{n}=101)\end{array}$ & $\begin{array}{l}\text { AIs } \\
(\mathrm{n}=97)\end{array}$ & $\mathrm{p}$ \\
\hline Mean age (range), years & $49.7(23-72)$ & $51.4(27-84)$ & $55.8(33-81)$ & 0.001 \\
\hline Duration of ET, mean (range), years & - & $2.6(0.8-4.8)$ & $2.5(0.8-4.4)$ & \\
\hline \multicolumn{5}{|l|}{ Marital status, \% } \\
\hline Single & 31 & 33 & 36 & \multirow{2}{*}{0.154} \\
\hline Married & 69 & 67 & 64 & \\
\hline \multicolumn{5}{|l|}{ Comorbidity, \% } \\
\hline No & 55 & 54 & 44 & \multirow[t]{2}{*}{0.753} \\
\hline Yes & 45 & 46 & 56 & \\
\hline \multicolumn{5}{|l|}{ Income, \% } \\
\hline$<1,000 \mathrm{TL}$ & 47 & 48 & 49 & \multirow[t]{3}{*}{0.982} \\
\hline $1,001-3,000 \mathrm{TL}$ & 41 & 42 & 41 & \\
\hline$>3,000 \mathrm{TL}$ & 12 & 10 & 10 & \\
\hline \multicolumn{5}{|l|}{ Education level, \% } \\
\hline Literate & 15 & 18 & 16 & \multirow[t]{3}{*}{0.500} \\
\hline Primary school & 45 & 39 & 51 & \\
\hline \multirow{2}{*}{\multicolumn{5}{|c|}{ Her $2, \%$}} \\
\hline & & & & \\
\hline Negative & 50 & 55 & 56 & \multirow[t]{2}{*}{0.276} \\
\hline Positive & 50 & 45 & 44 & \\
\hline \multicolumn{5}{|l|}{ Stage, $\%$} \\
\hline I-II & 48 & 60 & 56 & \multirow[t]{2}{*}{0.292} \\
\hline III-IV & 52 & 40 & 44 & \\
\hline \multicolumn{5}{|l|}{ Chemotherapy } \\
\hline No & 9 & 18 & 9 & \multirow[t]{2}{*}{0.076} \\
\hline Yes & 91 & 82 & 91 & \\
\hline
\end{tabular}

Table 1. Patient characteristics and quality of life scores 


\section{EORTC QLQ-C30}

To calculate a functional score (FS), the total score a patient acquired from 15 questions was divided into the total number of questions (15), and thereby a raw score (RS) was calculated. The difference between the highest (4) and the lowest scores (1) pertaining to the answers gave the range values (3). With these values, FS was calculated according to the following formula: $\mathrm{FS}=(1-(\mathrm{RS}-1) /$ range $) \times 100$.

In order to calculate a social functional score (SFS), the total score that a patient got from questions 26 and 27 was divided into the total number of questions (2), and thereby a RS was calculated. The difference between the highest (4) and the lowest scores (1) belonging to the answers gave the range values (3). With these values, SFS was calculated using the following formula: SFS $=(1-($ RS-1 $) /$ range $) \times 100$.

To calculate a symptom score (SS), the total score was divided into the total number of questions (13), out of which an RS was calculated. The difference between the highest (4) and the lowest scores pertaining to the answers (1) gave the range values (3). With these values, SS was calculated according to the following formula: $\mathrm{SS}=((\mathrm{RS}-1) /$ range $) \times 100$.

To calculate a fatigue score (FAS) in the symptom scale, the total score a patient obtained from questions 10,12 , and 18 was divided into the total number of questions (3), and thereby an RS was calculated. The difference between the highest (4) and the lowest scores concerning the answers (1) gave the range values (3). With these values, an FAS was calculated using the following formula: FAS $=(($ RS-1 $) /$ range $) \times 100$.

In order to calculate a general health score (GSS), the total score obtained from the last 2 questions was divided into the total number of questions (2), and then an RS was calculated. Again, the difference between the highest (7) and the lowest scores (1) was calculated as a range value. With this value, a GSS was calculated using the following formula: GSS $=(($ RS-1 $) /$ range $) \times 100$.

\section{SF-12}

The SF-12 questionnaire comprises a subset of 12 items from which the physical and mental components of the SF-12 are constructed as unique scores. These 12 items are used to construct the physical component summary (PCS) and the mental component summary (MCS) [8]. SF-12 PCS and MCS scores were generated based on a mean of 50 and a standard deviation of 10 using population norms [9].

\section{Statistical Analysis}

All statistical analyses were conducted using SPSS version 15.0 for Windows (SPSS Inc., Chicago, IL, USA). Patient characteristics were analyzed using the chi-square test and Student's t-test. For all evaluations, statistical significance was set at $\mathrm{p}<0.05$. The effect of ET on cognitive functions was assessed using univariate ANOVA. The correlation among different study groups was evaluated with Spearman's rank correlation analysis. When a calculated $\mathrm{p}$ value was significant $(\mathrm{p}<0.05)$, Bonferonni correction was performed. Also, a partial correlation analysis was performed to evaluate the correlation among the QoL scores.

\section{Results}

In this study, a total of 293 patients with breast cancer were evaluated. The study population consisted of 101 (34.5\%) patients receiving tamoxifen, 97 (33.1\%) patients receiving AIs, and 95 (32.4\%) patients not receiving any ET. Patient characteristics are summarized in table 1 . The mean age was significantly higher in patients treated with AIs compared to those receiving tamoxifen or those not receiving any ET (56 vs. 51 vs. 50, respectively; $\mathrm{p}<0.001$ ). The mean duration of ET was 2.6 years for tamoxifen and 2.5 years for AIs. Demographic features such as comorbidities, marital status, educational levels, and income were not significantly different among the 3 groups. Furthermore, disease stage, Her2 status, and use of chemotherapy were similar between the groups at the time of questionnaire completion. All QoL scores of the study population are presented in table 2. EORTC QLQ-C30 global scores and cognitive function scores as well as SF-12 mental scorings (MCS) were not significantly different between the 3 groups $(\mathrm{p}=0.529, \mathrm{p}=0.333$, and $\mathrm{p}=0.452$ for patients not receiving any ET, patients receiving tamoxifen, and patients receiving AIs, respectively). The calculated correlations are shown in table 3. SF-12 MCS correlated moderately with EORTC QLQ-C30 global scores for the 3 treatment groups (all $\mathrm{p}$ values $<0.001$ ). This correlation was also observed between the MCS and EORTC cognitive functioning ( $\mathrm{p}=$ 0.010 for the no ET group, $\mathrm{p}<0.001$ for the tamoxifen group, and $p=0.024$ for the AI group). In the subgroup analyses, no difference was observed in cognitive functions, global QoL scorings, and SF-12 MCS scorings when analyses were performed according to clinical parameters including age, educa-
Table 2. Quality of life scoring in the study population (mean \pm standard deviation)

\begin{tabular}{|c|c|c|c|c|}
\hline & No ET & TMX & AIs & $\mathrm{p}$ \\
\hline Global & $65.8 \pm 22.4$ & $66.5 \pm 22.5$ & $63.0 \pm 20.8$ & 0.529 \\
\hline Physical functioning & $70.5 \pm 17.8$ & $72.7 \pm 20.7$ & $64.6 \pm 23.4$ & 0.069 \\
\hline Role functioning & $78.6 \pm 27.2$ & $83.3 \pm 26.6$ & $80.2 \pm 29.5$ & 0.513 \\
\hline Emotional functioning & $76.2 \pm 21.3$ & $70.5 \pm 24.6$ & $66.5 \pm 26.0$ & 0.154 \\
\hline Cognitive functioning & $81.9 \pm 24.0$ & $76.7 \pm 25.4$ & $78.6 \pm 21.1$ & 0.333 \\
\hline Social functioning & $74.8 \pm 24.5$ & $81.5 \pm 25.7$ & $78.6 \pm 28.3$ & 0.216 \\
\hline Fatigue & $36.2 \pm 21.9$ & $36.2 \pm 26.9$ & $43.7 \pm 26.2$ & 0.299 \\
\hline Nausea and vomiting & $14.8 \pm 25.3$ & $8.7 \pm 17.9$ & $11.9 \pm 20.8$ & 0.164 \\
\hline Pain & $28.1 \pm 28.6$ & $26.9 \pm 29.5$ & $32.3 \pm 30.5$ & 0.614 \\
\hline Dyspnea & $12.9 \pm 20.7$ & $15.0 \pm 23.6$ & $19.1 \pm 28.5$ & 0.262 \\
\hline Insomnia & $28.6 \pm 31.2$ & $23.7 \pm 31.0$ & $33.3 \pm 34.9$ & 0.132 \\
\hline Appetite loss & $14.8 \pm 25.1$ & $10.8 \pm 21.7$ & $14.8 \pm 21.9$ & 0.609 \\
\hline Constipation & $14.8 \pm 27.0$ & $23.8 \pm 29.1$ & $15.9 \pm 26.7$ & 0.504 \\
\hline Diarrhea & $11.0 \pm 22.5$ & $7.9 \pm 18.5$ & $7.4 \pm 20.2$ & 0.968 \\
\hline SF-12 mental scoring (MCS) & $46.5 \pm 11.3$ & $47.7 \pm 10.7$ & $46.0 \pm 10.5$ & 0.452 \\
\hline SF-12 physical scoring (PCS) & $41.5 \pm 9.2$ & $43.3 \pm 9.4$ & $42.2 \pm 10.6$ & 0.129 \\
\hline
\end{tabular}

Kilickap/Hayran/Cakir/Cilingiroglu/

Erman/Buyukdamgaci/Ozisik 
Table 3. Correlation analysis among the study groups

\begin{tabular}{lll}
\hline & \multicolumn{2}{l}{ SF-12 mental scoring } \\
\cline { 2 - 3 } & $\mathrm{r}$ & $\mathrm{p}$ \\
\hline No endocrine therapy & 0.42 & $<0.001$ \\
$\quad$ EORTC global scoring & 0.27 & 0.010 \\
$\quad$ Cognitive functioning & 0.42 & $<0.001$ \\
TMX & 0.50 & $<0.001$ \\
$\quad$ EORTC global scoring & & $<0.001$ \\
Cognitive functioning & 0.53 & 0.024 \\
AIs & 0.24 & \\
EORTC global scoring & & \\
Cognitive functioning & &
\end{tabular}

TMX = Tamoxifen; AIs = aromatase inhibitors; SF-12 = Short Form-12; EORTC = European Organization for Research and Treatment of Cancer; $r=$ correlation coefficient.

tional level, income, chemotherapy use, comorbidities, and disease stage. Also, SF-12 MCS, PCS, and all EORTC QoL scores including cognitive functioning were similar between pre- and postmenopausal breast cancer patients.

\section{Discussion}

ET is a standard treatment approach in HR+ breast cancer. Current guidelines recommend that all women with $\mathrm{HR}+$ disease should receive at least 5 years of adjuvant ET [10]. The risk of recurrence in these patients is reduced by approximately $50 \%$ with the use of ET. It was reported recently that hormone therapy with AI alone or with sequential AI and tamoxifen in postmenopausal breast cancer patients resulted in lower recurrence rates compared to patients receiving tamoxifen alone. Despite favorable outcomes obtained with AIs, issues such as which AI is more beneficial or which scheme (upfront or sequential) is better are still unclear.

Although ET provides reduced recurrence, it may also cause undesirable effects like thrombosis, bone fractures, and endometrial carcinoma. These adverse effects are usually evaluated by physicians at the follow-up appointments. However, QoL and its subcomponents in patients receiving ET are generally underestimated. Cognitive function is one of the major components of QoL, and the effects of ET on cognitive functions and global QoL scores during or after therapy are still debated.

There are 2 different types of ER, namely ER-alpha and ER-beta, and these receptors are frequently distributed in different tissue and organs. In the brain, both receptors are expressed [11]. In preclinical studies, estradiol and related mediators were demonstrated to have a neuroprotective effect $[12,13]$. Tamoxifen binds to each ER with similar affinity. However, the effects of tamoxifen on brain tissue have not been well characterized. Ernst et al. [14] suggested that tamoxifen had an effect similar to that of estrogen on the brain and that both drugs might be neuroprotective. In another study, the authors evaluated the effects of estrogen and tamoxifen on brain function and structure [15]. The results of this study supported that although estrogen had a neuroprotective effect, tamoxifen plays an antagonistic role both in the frontal lobes and the hippocampus. Moreover, some experimental studies suggested that tamoxifen had little or no effect on cognitive function $[16,17]$. In contrast, some authors insist that the drug had detrimental effects on cognitive function due to its antiestrogenic effect [18].

The association between cognitive functions and AI use has been assessed in subgroup analyses in a number of clinical trials. In 1 of these studies, breast cancer patients receiving adjuvant letrozole for 5 years had better cognitive functions than those receiving tamoxifen [6]. The authors also evaluated cognitive functions in postmenopausal breast cancer patients during the 5 th year of treatment and 1 year after the end of treatment. The results showed that cognitive functions 1 year after the cessation of adjuvant ET were better compared to those at the 5th year of treatment [19].

It was reported from the IBIS-II study that there was no change in cognitive function with anastrozole use [20]. Memory functions were found to be impaired at 6 months with anastrozole but were similar between the 2 treatment arms at 24 months. Furthermore, the results of a substudy of the ATAC study demonstrated that the anastrozole group had worse verbal memory [21]. In another study, Bender et al. [22] evaluated the cognitive functions in patients treated with ET for at least 3 months. Memory as well as verbal and visual learning were poorer with anastrozole in comparison to tamoxifen. Those findings were consistent with the results of another study with a small sample size [23]. The mentioned studies suggest that hormonal therapies with both tamoxifen and anastrozole have negative effects on cognition.

In this study, ET with either tamoxifen or AIs was found to have no effect on cognitive function when compared to patients not receiving any ET. The outcomes of the QoL scoring including SF-12 MCS, EORTC QLQ-C30 global scores, and cognitive function scores were similar in all groups. Also, there was no difference between any of the study groups in terms of QoL scores when corrected for clinical parameters like educational level, income, chemotherapy use, and age. Similar to this study, the effect of adjuvant exemestane on cognitive function was assessed in the TEAM trial [24]. Cognitive functions were compared in 3 different groups consisting of patients receiving exemestane or tamoxifen and healthy controls. Cognitive functions were slightly better in the exemestane group than in healthy controls. However, all cognitive domains were found to be significantly worse in patients treated with tamoxifen than in those receiving exemestane and in healthy controls.

There are some limitations of this study. First of all, QoL assessment was performed in a cross-sectional design. If a comparison was to be performed using the questionnaires before and after treatment, the effects of ET on cognitive function and QoL could be more suitably identified. Another limitation was the duration of the use of ET. In this study, 
patients who received ET for a minimum of 6 months were included. However, cognitive functions may also be impaired due to long-term use of ET. Another limitation was that the AI group consisted of only patients receiving letrozole or anastrozole. Also, our patients received either AIs alone or sequential therapy following 2-3 years after tamoxifen. However, in those cases, the switch to tamoxifen from AIs occurred at least 6 months prior to the time of the questionnaire. In conclusion, our study suggests that cognitive functions and QoL scores are similar between patients receiving AIs or tamoxifen, and that receiving any ET changed neither cognitive functions nor QoL scores. Larger randomized prospective clinical trials are needed to support these findings.

\section{Acknowledgement}

This work was supported by the Scientific and Technological Research Council of Turkey.

\section{Disclosure Statement}

The authors declare that they have no competing interests. There are no financial interests to be disclosed for any of the authors.

\section{References}

1 American Cancer Society: Bridging the health care divide: overview of cancer disparities. $w w w$. cancer.org/docrootsubsite/cancerdisparities/content/ Cancer_Disparities_Overview.asp; 2007 (accessed September 7, 2008).

2 Coates AS, Keshaviah A, Thurlimann B, Mouridsen H, Mauriac L, Forbes JF, Paridaens R, Castiglione-Gertsch M, Gelber RD, Colleoni M, Láng I, Del Mastro L, Smith I, Chirgwin J, Nogaret JM, Pienkowski T, Wardley A, Jakobsen EH, Price KN, Goldhirsch A: Five years of letrozole compared with tamoxifen as initial adjuvant therapy for postmenopausal women with endocrine-responsive early breast cancer: update of study BIG 1-98. J Clin Oncol 2007;25:486-492.

3 Coombes RC, Hall E, Gibson LJ, Paridaens R, Jassem J, Delozier T, Jones SE, Alvarez I, Bertelli G, Ortmann O, Coates AS, Bajetta E Dodwell D, Coleman RE, Fallowfield LJ, Mickiewicz E, Andersen J, Lønning PE, Cocconi G, Stewart A, Stuart N, Snowdon CF, Carpentieri M, Massimini G, Bliss JM, van de Velde C; Intergroup Exemestane Study: A randomized trial of exemestane after two to three years of tamoxifen therapy in postmenopausal women with primary breast cancer. N Engl J Med 2004;350:1081-1092.

${ }_{4}$ Goss PE, Ingle JN, Martino S, Robert NJ, Muss HB, Piccart MJ, Castiglione M, Tu D, Shepherd LE, Pritchard KI, Livingston RB, Davidson NE, Norton L, Perez EA, Abrams JS, Cameron DA, Palmer MJ, Pater JL: Randomized trial of letrozole following tamoxifen as extended adjuvant therapy in receptorpositive breast cancer: updated findings from NCIC CTG MA.17. J Natl Cancer Inst 2005;97:1262-1271.

$\checkmark 5$ Baum M, Buzdar A, Cuzick J, Forbes J, Houghton J, Howell A, Sahmoud T; ATAC (Arimidex, Tamoxifen Alone or in Combination) Trialists' Group: Anastrozole alone or in combination with tamoxifen versus tamoxifen alone for adjuvant treatment of postmenopausal women with early-stage breast cancer: results of the ATAC (Arimidex, Tamoxifen Alone or in Combination) trial efficacy and safety update analyses. Cancer 2003;98:1802-1810.
6 Phillips KA, Ribi K, Sun Z, Stephens A, Thompson A, Harvey V, Thürlimann B, Cardoso F, Pagani O, Coates AS, Goldhirsch A, Price KN, Gelber RD, Bernhard J: Cognitive function in postmenopausal women receiving adjuvant letrozole or tamoxifen for breast cancer in the BIG 1-98 randomized trial. Breast 2010;19:388-395.

7 Hermelink K, Henschel V, Untch M, Bauerfeind I, Lux MP, Munzel K: Short-term effects of treatment-induced hormonal changes on cognitive function in breast cancer patients. Cancer 2008; 113:2431-2439.

8 Gandek B, Ware JE, Aaronson NK, Apolone G, Bjorner JB, Brazier JE, Bullinger M, Kaasa S, Leplege A, Prieto L, Sullivan M: Cross-validation of item selection and scoring for the sf- 12 health survey in nine countries: results from the IQOLA project. International Quality of Life Assessment. J Clin Epidemiol 1998;51:1171-1178.

9 Ware JE, Kosinski M, Keller SD: SF-12: How to Score the SF-12 Physical and Mental Health Summary Scales. 3rd ed. Lincoln, RI, QualityMetric Inc; 1998.

10 National Comprehensive Cancer Network: Clinical Practice Guidelines in Oncology. Breast Cancer. www.nccn.org/professionals/physician_gls/PDF/ breast.pdf; 2009.

11 Shughrue PJ, Merchenthaler I: Estrogen is more than just a 'sex hormone': novel sites for estrogen action in the hippocampus andcerebral cortex. Front Neuroendocrinol 2000;21:95-101.

12 Brann DW, Dhandapani K, Wakade C, Mahesh VB, Khan MM: Neurotrophic and neuroprotective actions of estrogen: basic mechanisms and clinical implications. Steroids 2007;72:381-405.

13 Bryant D, Sheldahl L, Marriott L, Shapiro RA, Dorsa DM: Multiple pathways transmit neuroprotective effects of gonadal steroids. Endocrine 2006;29:199-207.

14 Ernst T, Chang L, Cooray D, Salvador C, Jovicich J, Walot I, Boone K, Chlebowski R: The effects of tamoxifen and estrogen on brain metabolism in elderly women. J Natl Cancer Inst 2002;94:592-597.

15 Eberling JL, Wu C, Tong-Turnbeaugh R, Jagust WJ: Estrogen-and tamoxifen-associated effects on brain structurexand function. Neuroimage 2004;21:364371.
16 Schagen SB, van Dam FS, Muller MJ, Boogerd W, Lindeboom J, Bruning PF: Cognitive deficits after postoperative adjuvant chemotherapy for breast carcinoma. Cancer 1999;85:640-650.

17 Van Dam FS, Schagen SB, Muller MJ, Boogerd W, vd Wall E, Droogleever Fortuyn ME, Rodenhuis S: Impairment of cognitive function in women receiving adjuvant treatment for high-risk breast cancer: high-dose versus standard-dose chemotherapy. J Natl Cancer Inst 1998;90:210-218.

18 Arpels JC: The female brain hypoestrogenic continuum from the premenstrual syndrome to menopause. J Reprod Med 1996;41:633-639.

19 Phillips KA, Aldridge J, Ribi K, Sun Z, Thompson A, Harvey V, Thürlimann B, Cardoso F, Pagani O, Coates AS, Goldhirsch A, Price KN, Gelber RD, Bernhard J: Cognitive function in postmenopausal breast cancer patients one year after completing adjuvant endocrine therapy with letrozole and/or tamoxifen in the BIG 1-98 trial. Breast Cancer Res Treat 2011;126:221-226.

20 Jenkins VA, Ambroisine LM, Atkins L, Cuzick J, Howell A, Fallowfield LJ: Effects of anastrozole on cognitive performance in postmenopausal women: a randomised, double-blind chemoprevention trial (IBIS II). Lancet Oncol 2008;9:953-961.

21 Shilling V, Jenkins V, Fallowfield L, Howell T: The effects of hormone therapy on cognition in breast cancer. J Steroid Biochem Mol Biol 2003;86:405412.

22 Bender CM, Sereika SM, Brufsky AM, Ryan CM, Vogel VG, Rastogi P, Cohen SM, Casillo FE, Berga SL: Memory impairments with adjuvant anastrozole versus tamoxifen in women with earlystage breast cancer. Menopause 2007:14:995-998.

23 Collins B, Mackenzie J, Stewart A, Bielajew C, Verma S: Cognitive effects of hormonal therapy in early stage breast cancer patients: a prospective study. Psychooncology 2009;18:811-821.

24 Schilder CM, Eggens PC, Seynaeve C, Linn SC, Boogerd W, Gundy CM, Beex LV, Van Dam FS, Schagen SB: Neuropsychological functioning in postmenopausal breast cancer patients treated with tamoxifen or exemestane after AC-chemotherapy: cross-sectional findings from the neuropsychological TEAM-side study. Acta Oncol 2009;48:76-85. 